\title{
THE PRELIMINARY ASSESSMENT OF ADAPTATION POTENTIAL IN EXISTING OFFICE BUILDINGS
}

\author{
Sara WILKINSON ${ }^{\mathrm{a}, *}$ \\ a School of Built Environment, University of Technology, Sydney, POB 123 Broadway Ultimo, Sydney, \\ New South Wales 2007, Australia
}

Received 17 April 2012; accepted 4 November 2012

\begin{abstract}
It is said that the battle for sustainability will be won or lost in the world's cities and a major tactic in this challenge will be the sustainable adaptation of existing buildings. Evidence based decision-making tools are required for the management of built assets. This research examined every building adaptation event between 1998 and 2008 with the relative importance of property attributes derived using a principal component analysis (PCA), from which a weighted index of optimal decisionmaking attributes in a predictive model was proposed; the Preliminary Assessment Adaptation Model (PAAM). The model is discussed and applied in an illustrative case study. Given further development and testing the PAAM might be useable by non-experts and property managers to appraise the suitability of a building for potential adaptation.
\end{abstract}

KEYWORDS: Building adaptation; Decision-making tool; Office buildings; Australia

REFERENCE to this paper should be made as follows: Wilkinson, S. 2014. The preliminary assessment of adaptation potential in existing office buildings, International Journal of Strategic Property Management 18(1): 77-87.

\section{INTRODUCTION}

Progressively more cities are aiming to become carbon neutral in the coming ten to fifteen years, for example San Francisco in the USA and Melbourne in Australia (City of Melbourne 2005). Many strategies are based on delivering substantial greenhouse gas emissions (GHG) reductions through sustainable adaptation of existing buildings. The City of Melbourne is advised that 38\% GHG reductions are possible through the adaptation of 1200 office buildings (Lorenz et al. 2008). Such an ambitious strategy demands a greater understanding of the relationships between office buildings and adaptation in order to capitalise on existing patterns of adaptation and to identify those sectors of the market which are least likely to undergo adaptation. This research sought to discuss, develop and demonstrate a decision-making model for non-experts to gain a deeper understanding of a building's adaptation potential for an 'alterations and extension' level adaptation in the Melbourne

\footnotetext{
* Corresponding author. E-mail: sara.wilkinson@uts.edu.au
}

central business district (CBD). The model does not apply for change of use adaptations.

\section{BUILDING ADAPTATION AND PROPERTY ATTRIBUTES}

Building adaptation is classified as "any work to a building over and above maintenance to change its capacity, function or performance. [or]'any intervention to adjust, reuse, or upgrade a building" (Douglas 2006:1). It is a broad definition and enables an analysis of a wide range of building adaptations both within use and across use and embraces minor to major works. In the context of this research 'adaptation' refers to changes to buildings and not to the measures used to respond to consequences of climate change.

Property attributes are deemed to be the political, economic, environmental, social, regulatory, locational and technological features and factors which influence adaptation. In an extensive literature review, the numerous attributes relating 
to adaptation were identified and categorised according to previous studies (reported in Wilkinson et al. 2009; Wilkinson, Reed 2011). In summary the attributes shown in Table 1, influence adaptation to some degree, though the extent of influence varies from project to project according to the prevailing local market conditions.

Table 1. Property attributes influencing adaptation

\begin{tabular}{|c|c|}
\hline Category & Attribute \\
\hline Economic & $\begin{array}{l}\text { Current value } \\
\text { Investment value } \\
\text { Yields } \\
\text { Increase in value post adaptation } \\
\text { Construction and development costs } \\
\text { Convertibility (ease of conversion to } \\
\text { other use and costs associated with the } \\
\text { conversion) }\end{array}$ \\
\hline Physical & $\begin{array}{l}\text { Building height/number of storeys } \\
\text { Floor plate size } \\
\text { Shape of floor plate } \\
\text { Service core location } \\
\text { Elasticity (ability to extend laterally or } \\
\text { vertically) } \\
\text { Degree of attachment to other buildings } \\
\text { Access to building } \\
\text { Height of floors } \\
\text { Structure } \\
\text { Floor strength } \\
\text { Distance between columns } \\
\text { Frame } \\
\text { Deconstruction (safe efficient } \\
\text { and speedily) } \\
\text { Expandability (volume and capacity) } \\
\text { Flexibility (space planning) } \\
\text { Technological and convertibility } \\
\text { Dis-aggregability } \\
\text { (reusability / recyclability) }\end{array}$ \\
\hline $\begin{array}{l}\text { Location } \\
\text { and land use }\end{array}$ & $\begin{array}{l}\text { Transport } \\
\text { Access (proximity to airports, motorways, } \\
\text { train stations, public transport nodes, } \\
\text { buses and trams) } \\
\text { Land uses (commercial, residential, } \\
\text { retail and industrial or mixed use such } \\
\text { as office and retail) } \\
\text { Existing planning zones } \\
\text { Rezoning potential } \\
\text { Density of occupation }\end{array}$ \\
\hline Legal & $\begin{array}{l}\text { Ownership - tenure } \\
\text { Occupation - multiple or single tenants } \\
\text { Building codes } \\
\text { Fire codes } \\
\text { Access acts } \\
\text { Health and safety issues } \\
\text { Convertibility }\end{array}$ \\
\hline Social & $\begin{array}{l}\text { Community benefits - historic listing } \\
\text { Transport noise } \\
\text { Retention of cultural past } \\
\text { Urban regeneration } \\
\text { Aesthetics } \\
\text { Provision of additional } \\
\text { facilities / amenities } \\
\text { Proximity to hostile factors } \\
\text { Stigma } \\
\text { Age }\end{array}$ \\
\hline Environmental & $\begin{array}{l}\text { Internal air quality } \\
\text { Internal environment quality } \\
\text { Existence of hazardous materials } \\
\text { (asbestos) } \\
\text { Sustainability issues }\end{array}$ \\
\hline
\end{tabular}

In Wilkinson and Reed (2011), there is an extended discussion on the influencing attributes and measurement issues which cover the extent and limitations of other decision making models relating to adaptation. Furthermore the paper details the six levels of adaptation used in this research labelled; level 1 'minor', level 2 'alterations', level 3 'change of use', level 4 'alterations and extensions', level 5 'new build' and level 6 'demolition' (Wilkinson, Reed 2011). Using the six levels of adaptation and the influencing factors in Table 1 a conceptual model was proposed (Fig. 1).

Though Chudley (1981) never produced a model as such, this conceptual model is largely based on his work. In the early 1980s Chudley (1981) was endeavouring to establish a sequence of steps or decisions which need to be taken in order to undertake a robust initial assessment of the suitability of an individual building for adaptation. This framework covered all the groupings identified by other researchers who have published in the field, bar environmental issues which are now incorporated. The preliminary decision-making model shown in Fig. 2 extends the concept by identifying exit points at decision points.

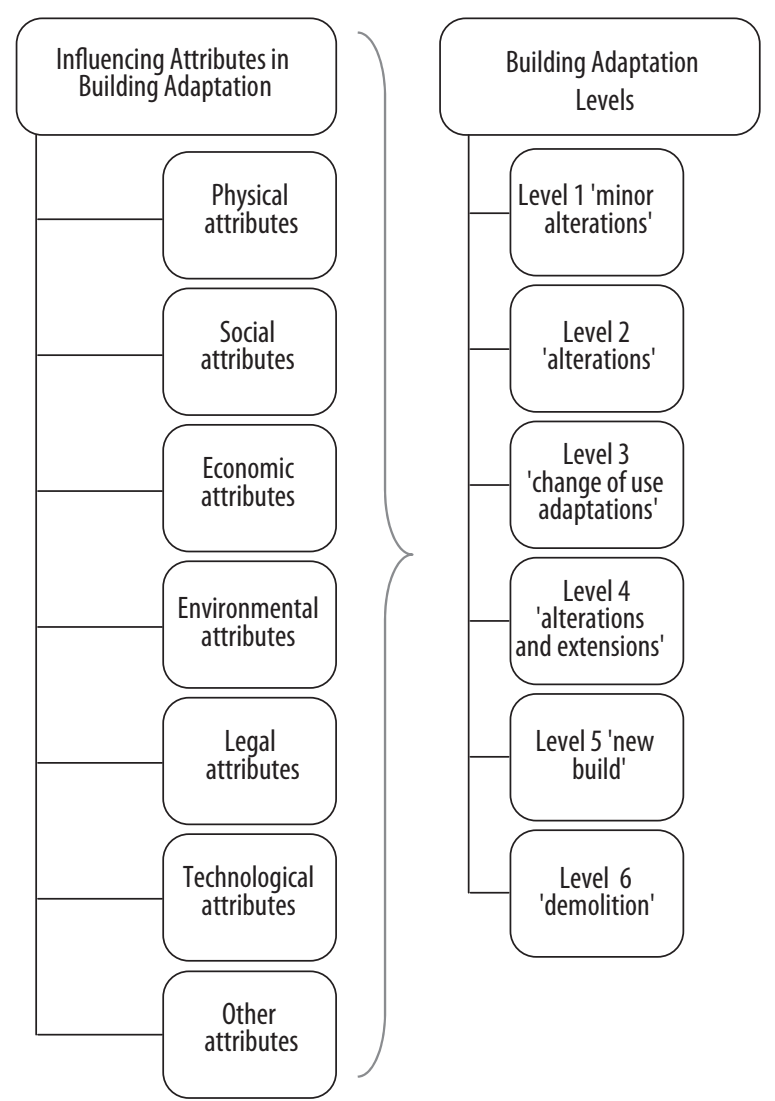

Fig. 1. Conceptual model of influencing attributes and levels of building adaptation 


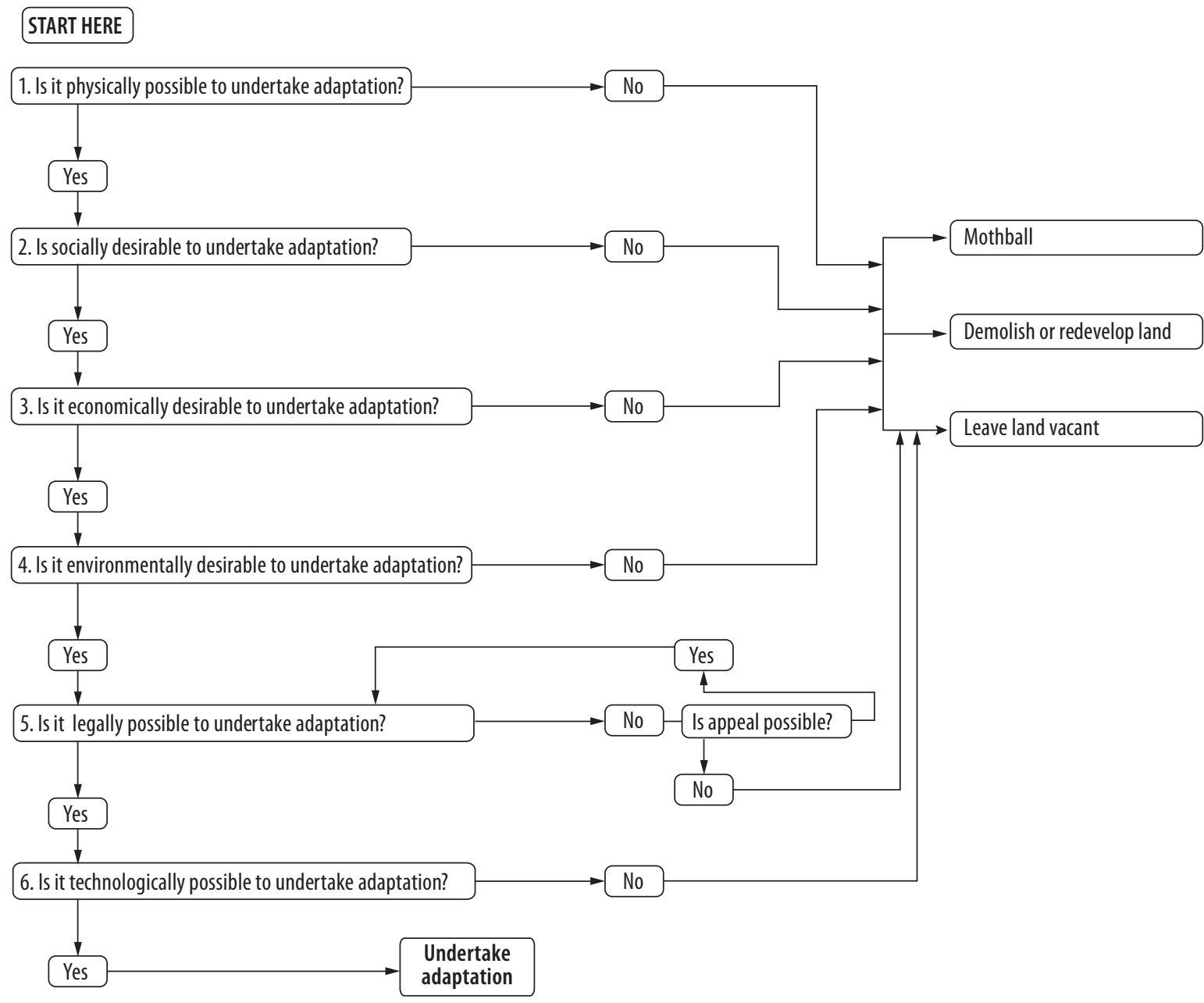

Fig. 2. Decision making model of building adaptation

The key revisions to Chudley's framework are the indication of options for stakeholders incorporated at each stage and the sequence of consideration of the factors which is based on the summarised findings of research into building adaptation. The revised ordering is a significant difference and reflects the rank order of weighting based on the findings of previous studies conducted by Arge (2005), Kincaid (2002), Ball (2002) and Remøy and van der Voordt (2007).

\section{RESEARCH METHODOLOGY}

The first stage of the research method outlining the issues around earlier studies into building adaptation and the compilation of a building attribute database is reported in Wilkinson and Reed (2011). Previous studies largely used a case study approach with detailed analysis of small samples of buildings (Ohemeng 1996; Blakstad 2001; Heath 2001; Ball 2002; Kincaid 2002; Kucik 2004; Arge 2005; Remøy, van der Voordt 2007). From these studies adaptation criteria were identified and formed the fields for the building attribute database. The fields were populated with data from multiple sources including 'Cityscope' (RPData 2008), 'PRISM' produced by the State Government of Victoria's Department of Sustainability and Environment (DSE 2008) and the Property Council of Australia (Property Council of Australia 2007, 2008). Building adaptation events were extracted from building permits received from the Victorian Building Commission with supporting information gathered and validated by visual building surveys. Every building adaptation event between 1998 and 2008 in the CBD is examined and the results are representative. The $\mathrm{CBD}$ was selected as it is the most mature property market in Victoria being continuously occupied since the 1830s.

The methodology has to satisfy criteria of internal and external validity and reliability (De Vaus 2002). Reliability relates to consistency. The raw data must be coded in such a way that another researcher can understand the themes and arrive at similar conclusions. The coding scheme that was selected involved using the adaptation 
attributes found in the literature to be valid. The concept of external validity refers to the generalisability of the findings of the study, and here because all adaptation events were captured in the database there is no issue about external validity of the results as applied to Melbourne CBD. Furthermore given the nature of the social, economic, environmental and physical characteristics of the Melbourne CBD building stock, it is likely that the results are applicable to other cities in Australia and internationally. The question of the validity of the PCA process depends on the accuracy of the data inputting into the database which took eight months to complete and the measures used on the PCA. Best practice guidelines were followed in the application of the PCA to ensure the accuracy of the results.

\subsection{Principal Component Analysis (PCA)}

PCA is a mathematical technique using orthogonal transformation to convert a set of conceivably correlated variables into a set of values of linearly uncorrelated variables named principal components (Jolliffe 2002). The transformation is defined so that the first principal component has the largest possible variance; it accounts for as much variability in the data as possible. PCA condenses information in a number of initial variables into a smaller set of new composite factors with a least loss of information (Hair et al. 1995) here; to reduce the dimensionality of office building attribute data. PCA is mostly used as a tool in exploratory data analysis and for making predictive models. The technique is a reliable, proven method of highlighting dimensions in cross sectional data to uncover, disentangle and summarise patterns of correlation within a data set (Heikkila 1992; Horvath 1994).

All property attributes were examined to identify the degree of variance explained with the objective being to identify the highest level of variance explained by an interpretable group of components. Initially all variables were entered into the PCA to produce a smaller number of components where factors with Eigenvalues exceeding 1.0 were retained. The factors were rotated using an oblique 'Oblimin' rotation method with a final result being a table of identifiable factors which includes the loadings of individual building attributes. For those who are interested in sustainability of office buildings, but not cognisant of the mathematics underpinning PCA, further information see Smith (2002) and Wilkinson (2011).

7,393 building adaptation events occurred between 1998 and 2008 for which full address details were determined. These events occur to whole buildings or to parts of buildings. Assigning meaning involves interpretation of the pattern of the factor loadings and this is somewhat subjective (Hair et al. 1995), though it is based on the coding system derived from the literature review. With the list of each factor containing high loading building attribute variables, the researcher assigned factor names. This analysis examined all 5290 events classed as 'alterations and extensions' the most extensive degree of adaptation in the study. For a full description of the procedures followed in the PCA and the discussion of the retained attributes see Wilkinson and Reed (2011). After thirty three PCA iterations 12 attributes were found to account for $73 \%$ of the original variance and formed the starting point for the PAAM (Table 2).

Table 2. Summary of PCA factors 'alterations and extensions' adaptations

\begin{tabular}{|c|c|c|}
\hline $\begin{array}{l}\text { Factor } \\
\text { number }\end{array}$ & $\begin{array}{l}\text { Factor name } \\
\text { (\% of variance explained) }\end{array}$ & $\begin{array}{l}\text { Factor attributes } \\
\text { (\% of variance explained within factor) }\end{array}$ \\
\hline 1 & Physical and size (44.86\%) & $\begin{array}{l}\text { Number of storeys }(19.19 \%) \\
\text { Gross floor area }(19.19 \%) \\
\text { Property Council of Australia building quality grade }(16.46 \%) \\
\text { Degree of attachment to other buildings }(15.52 \%) \\
\text { Typical floor area }(14.88 \%) \\
\text { Site access }(14.76 \%)\end{array}$ \\
\hline 2 & Land (19.78\%) & $\begin{array}{l}\text { Street frontage }(36.28 \%) \\
\text { Vertical services location }(35.26 \%) \\
\text { Property location }(28.46 \%)\end{array}$ \\
\hline 3 & Social $(9.32 \%)$ & $\begin{array}{l}\text { Historic listing }(42.42 \%) \\
\text { Age in } 2010(32.58 \%) \\
\text { Aesthetics }(25.00 \%)\end{array}$ \\
\hline
\end{tabular}




\subsection{The Preliminary Adaptation Assessment Model (PAAM)}

The objective is that the PAAM would be used by a non expert to make an initial assessment of a building's general suitability for 'alterations and extensions' adaptations. A new model in the light of the results of the PCA is proposed based initially on the Chudley (1981) framework which was complex, contained little detail and did not clearly categorise attributes. In addition, the PAAM incorporated more recent developments such as environmental sustainability.

The sequencing of the attribute groups in Fig. 2 such as 'physical' and 'economic' is based on the work of Chudley (1981) and others (Arup 2008; Kincaid 2002) as a logical means of evaluating different attributes in order of perceived importance. Chudley (1981) and others (Kincaid 2002; Arup 2008) were unable to identify or weight the adaptation attributes they evaluated in their models in any order of importance because this research had not been undertaken, until now. This research fills this gap in knowledge and as a result, the ordering of attribute groupings from most to least important is now possible. The order of importance of physical, social, economic, environmental and regulatory attributes was tested in the PCA. Chudley's model is generic and is designed to apply to all adapta- tions whereas the new model proposed in Fig. 3 relates to 'alterations and extensions' adaptations in office buildings only.

Qualitative estimation of adaptation potential of each attribute is based on the percentage of occurrence derived from previous adaptations measured in the model. For each property attribute, the percentages of occurrence are standardised between 0 and 1 and a grading score is allocated which can be; very high (0.81-1.00), high (0.61$0.80)$, medium $(0.41-0.60)$, low $(0.21-0.40)$ or very low $(0.00-0.20)$.

For example, the attribute Property Council of Australia building quality grade (Figure 4), the assessor poses the question; 'what is the existing Property Council of Australia building quality grade?' The possible answers are; B grade (27.42\%), ungraded (22.05\%), A (21.49\%), premium grade (14.09\%), C grade (11.05\%) or D grade $(3.90 \%)$ in order of the percentage of occurrence derived from previous adaptations measured in the model. These percentages are standardised and allocated a score as follows:

Percentages; $\mathrm{P} 1=0.27, \mathrm{P}=0.22, \mathrm{P} 3=0.21$, $\mathrm{P} 4=0.14, \mathrm{P} 5=0.11, \mathrm{P} 6=0.04$.

- Step 1. Identify highest value P1; $0.27=1$.

- Step 2. Identify lowest value P6; $0.04=0$.

- Step 3. Calculate the values for the intermediate answers using the equation:

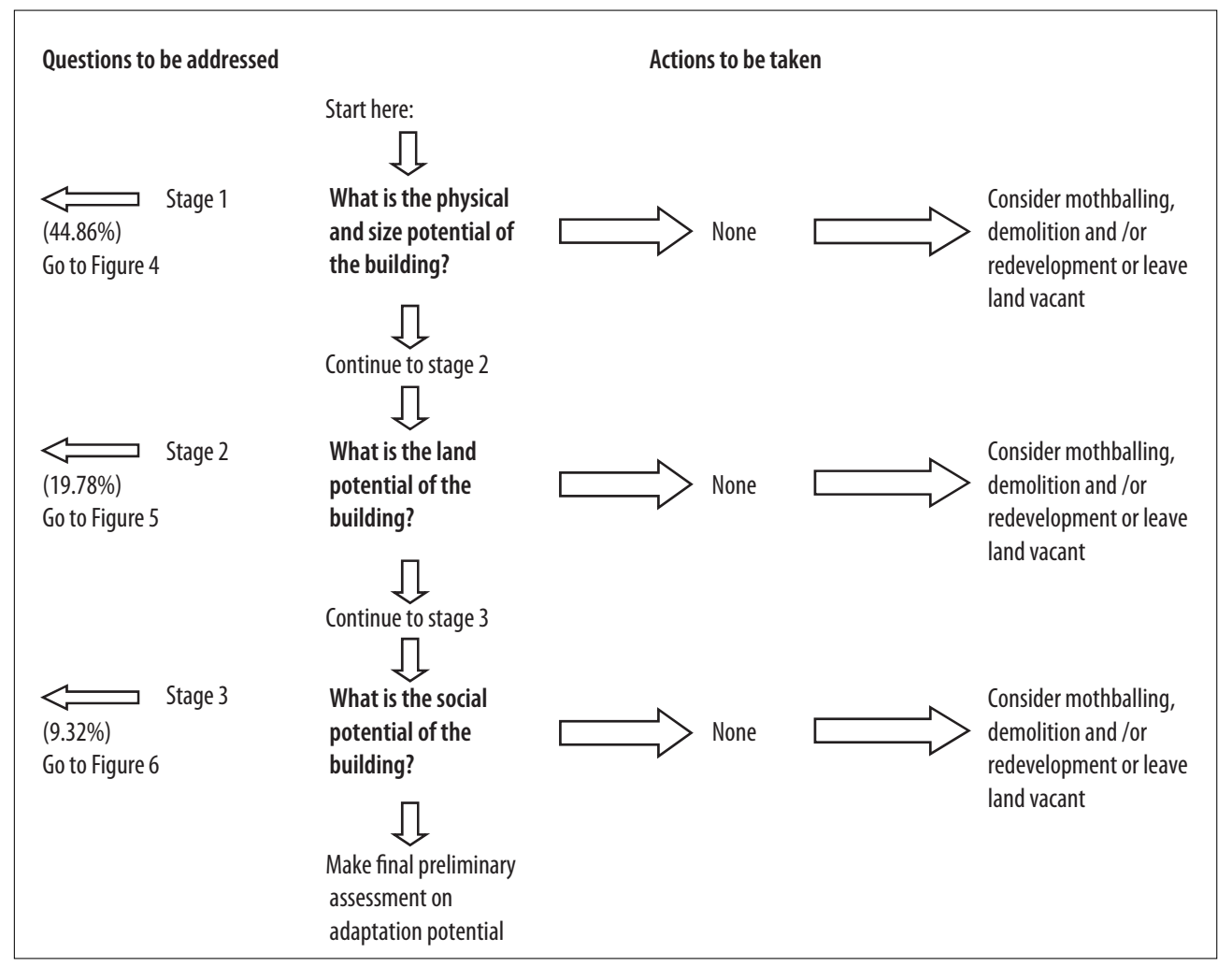

Fig. 3. 'Alterations and extensions' adaptations PAAM 
$\frac{\text { Value }- \text { Minimum }}{\text { Maximum-Minimum }} \frac{0.22-0.40}{0.27-0.04}=\frac{0.18}{0.23}=0.78$.

The standardised values are $\mathrm{P} 1=1, \mathrm{P} 2=0.78$, $\mathrm{P} 3=0.74, \mathrm{P} 4=0.43, \mathrm{P} 5=0.30, \mathrm{P} 6=0$. Based on this approach the final scores for the Property Council of Australia building quality grade are then based on the grading score above and are as follows:

- Grade B final score 1 = Very high.

- Ungraded final score $0.78=$ High.

- Grade A final score $0.74=$ High.

- Premium final score $0.43=$ Medium.

- Grade C final score $0.30=$ Low.

- Grade D final score $0=$ Very low.

This standardisation approach is a useful qualitative aid to scoring the answers where there are more than two options however scoring two options remains subjective. The grading is based on the evaluation of 5290 previous adaptations in the $\mathrm{CBD}$ and it is acknowledged that this approach does produce apparent anomalies where for example a building of 19-42 years has a 'high' score and a building aged over 42 years is graded 'low'. The grading is based on a statistical analysis of what the Melbourne CBD market has done with respect to building adaptation over the period 1998 to 2008. It is accepted that all things being equal, and that logic would suggest that older buildings may typically be more worn or out-dated than younger ones but the evidence in Melbourne has been that buildings in the 19-42 year age range are far more likely to under adaptation than older ones. Over the time period covered by this study, office buildings aged 19-42 years underwent more adaptation than those aged under 19 years and over 42 years. The reasons for this are unknown and not explored within this study but could be a result of owner and economic drivers, and or the predominance of certain physical characteristics inherent in the scale, design and construction methods and materials found in this stock. This is an aspect for further investigation.

The next step is to score each group of graded attributes within a factor and finally the overall building PAAM grading. Using a case study for 'alterations and extensions' adaptations as an example (Table 3); the table shows how the six attributes graded in factor one. There are two 'very low', three 'very high' and one 'high' grade. The two 'very low' and 'very high' grades cancel each other out and the remaining overall grade for factor one physical and size is 'very high / high'. The three factors are then evaluated to make an overall grade, in this case 'very high/high', 'very high' and 'very high' give a grade of 'very high' on the basis that factor one accounts for $44.86 \%$ of total variance and the remaining two factors account for $19.78 \%$ and 9.32\% respectively (Fig. 3).

Fig. 4 poses six questions relating to key property attributes identified in factor one of the 'alterations and extensions' adaptations PCA. The first attribute concerns the number of storeys in the building (height) and is weighted at 19.19\% of the variance of factor one. The second consideration is gross floor area which is divided into three categories representing small, medium and large buildings. The third attribute is the existing Property Council of Australia building quality grade which is weighted at $16.46 \%$ of the factor. The next attribute is the degree of attachment to other properties, weighted at $15.52 \%$ of the factor. Typical floor area is the fifth attribute to evaluate and is divided into four categories. The final attribute in factor one is site access, weighted at $14.76 \%$ and classified into five options with buildings having access on all sides being most likely to be adapted.

Having answered the six questions relating to physical and size attributes, the results give a reliable indication whether the building has good potential for adaptation (Fig. 4). After all questions have been answered, it is possible to determine whether to proceed to factor two or consider the other options. For example, if a building has nine storeys, has a gross floor area of $30,000 \mathrm{~m}^{2}$, is a Property Council of Australia Grade B office, is detached and can be accessed from all sides it has a very high potential for 'alterations and extensions' adaptation. Conversely, if the building has less than six storeys, has a Property Council of Australia Grade D rating, is attached on three sides and has access from the street and rear only it has much lower potential for an 'alterations and extensions' adaptation.

Factor two explains $19.78 \%$ of the total variance in 'alterations and extensions' adaptations, and comprises three attributes labelled 'land'. The attributes are street frontage, vertical services location and property location (Fig. 4). The first attribute, street frontage, is weighted at $36.28 \%$ of factor two. Narrow buildings were least likely to undergo adaptation whilst medium width property was most likely to be adapted.

The next attribute, vertical services location is weighted at $35.26 \%$ of factor two. Centrally located services were most likely to be adapted, followed by multiple locations and 'other locations' at $10.92 \%$. The final attribute in factor two is property location, weighted at $28.46 \%$. Low prime location was the most likely for adaptations followed closely by 


\begin{tabular}{|c|c|c|c|c|}
\hline $\begin{array}{l}\text { Weighting } \\
\text { (\% of factor variance) }\end{array}$ & Question & $\begin{array}{l}\text { Grading scale } \\
\text { (outcomes in rank order) }\end{array}$ & Notes & $\begin{array}{l}\text { Result and grade } \\
\text { selected }\end{array}$ \\
\hline $19.19 \%$ & $\begin{array}{l}\text { Number of } \\
\text { storeys? }\end{array}$ & $\begin{array}{l}7-20 \text { storeys. Very high. } \\
21-45 \text { storeys. High. } \\
\geq 46 \text { storeys. Very low. } \\
\leq 6 \text { storeys. Very low. }\end{array}$ & $\begin{array}{l}7-20 \text { storeys }(43.71 \%) . \\
21-45 \text { storeys }(30.92 \%) . \\
\geq 46 \text { storeys }(15.98 \%) \\
\leq 6 \text { storeys }(9.39 \%) .\end{array}$ & \\
\hline 0.19 & Gross floor area? & $\begin{array}{l}\leq 50,000 \mathrm{~m}^{2} \text {. Very high. } \\
50,001-100,000 \mathrm{~m}^{2} \cdot \text { Low. } \\
\geq 100,001 \mathrm{~m}^{2} \text {. Very low. }\end{array}$ & $\begin{array}{l}\leq 50,000 \mathrm{~m}^{2}(57.73 \%) \\
50,001-100,000 \mathrm{~m}^{2}(27.93 \%) \\
\geq 100,001 \mathrm{~m}^{2} .(14.35 \%)\end{array}$ & \\
\hline 0.16 & $\begin{array}{l}\text { Property Council of Australia } \\
\text { building quality grade? }\end{array}$ & $\begin{array}{l}\text { Grade B. Very high. } \\
\text { Ungraded. Very high. } \\
\text { Grade A. Very high. } \\
\text { Premium. Medium. } \\
\text { Grade C. Low. } \\
\text { Grade D. Very low. }\end{array}$ & $\begin{array}{l}\text { Grade B (27.42\%). } \\
\text { Ungraded (22.05\%). } \\
\text { Grade A (21.49\%). } \\
\text { Premium (14.09\%). } \\
\text { Grade C (11.05\%) } \\
\text { Grade D (3.90\%). }\end{array}$ & \\
\hline 0.16 & $\begin{array}{l}\text { Degree of attachment to other } \\
\text { buildings? }\end{array}$ & $\begin{array}{l}\text { Detached. Very high. } \\
\text { Attached on two sides. Medium. } \\
\text { Attached on one sides. Very low. } \\
\text { Attached on three sides. Very low. }\end{array}$ & $\begin{array}{l}\text { Detached (52.39\%). } \\
\text { Attached on two sides (23.90\%). } \\
\text { Attached on one side(15.05\%). } \\
\text { Attached on three sides (8.26\%). }\end{array}$ & \\
\hline 0.15 & Typical floor area? & $\begin{array}{l}701-1178 \mathrm{~m}^{2} \cdot \text { Very high. } \\
1179-1346 \mathrm{~m}^{2} \text {. Very high. } \\
\leq 700 \mathrm{~m}^{2} \text { Very low. } \\
\geq 1347 \mathrm{~m}^{2} \text { Very low. }\end{array}$ & $\begin{array}{l}701-1178 \mathrm{~m}^{2}(27.11 \%) . \\
1179-1346 \mathrm{~m}^{2}(26.26 \%) . \\
\leq 700 \mathrm{~m}^{2}(23.74 \%) \\
\geq 1347 \mathrm{~m}^{2}(22.89 \%)\end{array}$ & \\
\hline 0.15 & Site access? & $\begin{array}{l}\text { Street, side and rear access. Very high. } \\
\text { Street and side access. High. } \\
\text { Street only. Low. } \\
\text { Street and rear access. Low. } \\
\text { Access all sides. Very low. }\end{array}$ & $\begin{array}{l}\text { Street, side and rear (40.96\%). } \\
\text { Street and side (27.00\%). } \\
\text { Street only (15.65\%). } \\
\text { Street and rear access (12.62\%). } \\
\text { Access all sides (3.76\%). }\end{array}$ & \\
\hline
\end{tabular}

Fig. 4. 'Alterations and extensions' adaptations predictive model - factor one (physical and size)

\begin{tabular}{|c|c|c|c|c|}
\hline $\begin{array}{l}\text { Weighting } \\
\text { (\% of factor variance) }\end{array}$ & Question & $\begin{array}{l}\text { Grading scale } \\
\text { (outcomes in rank order) }\end{array}$ & Notes & $\begin{array}{l}\text { Result and grade } \\
\text { selected }\end{array}$ \\
\hline $36.28 \%$ & Street frontage? & $\begin{array}{l}\text { Medium }(20.01-40 \mathrm{~m}) \text {. Very high. } \\
\text { Extra wide }(60.01-201.25 \mathrm{~m}) \text {. High. } \\
\text { Wide }(40.01-60 \mathrm{~m}) \text {. Medium. } \\
\text { Narrow }(\leq 20 \mathrm{~m}) \text {. Very low. }\end{array}$ & $\begin{array}{l}\text { Medium }(37.79 \%) . \\
\text { Extra wide }(28.07 \%) . \\
\text { Wide }(22.83 \%) \\
\text { Narrow }(11.32 \%) .\end{array}$ & \\
\hline $35.26 \%$ & $\begin{array}{l}\text { Vertical services loca- } \\
\text { tion? }\end{array}$ & $\begin{array}{l}\text { Central location. Very high. } \\
\text { Multiple locations. Medium. } \\
\text { Elsewhere Very Low. }\end{array}$ & $\begin{array}{l}\text { Central (54.06\%). } \\
\text { Multiple (35.02\%). } \\
\text { Elsewhere (10.92\%). }\end{array}$ & \\
\hline $28.46 \%$ & Building location? & $\begin{array}{l}\text { Low prime. Very high. } \\
\text { High secondary. Very high. } \\
\text { Prime. Low. } \\
\text { Low secondary. Low. } \\
\text { Fringe. Very low. }\end{array}$ & $\begin{array}{l}\text { Low prime (27.03\%). } \\
\text { High secondary (25.75\%). } \\
\text { Prime (25.27\%). } \\
\text { Low secondary (13.41\%). } \\
\text { Fringe }(8.53 \%) .\end{array}$ & \\
\hline Total 100 & & & & \\
\hline
\end{tabular}

Fig. 5. 'Alterations and extensions' adaptations predictive model - factor two (land)

low secondary and prime, with those buildings in fringe locations least likely to be adapted.

When all questions are addressed the responses indicate the suitability for 'alterations and extensions' adaptation. A narrow building in the fringe location with services located to the side of the property scores 'very low' and is unlikely to undergo adaptation, whereas a medium width property, with centrally located services in the low prime location scores high and is more likely to undergo adaptation based on previous experience. The next stage is to evaluate factor three attributes (Fig. 6) which explain $9.32 \%$ of the total variance and contain three attributes labelled 'social'. 


\begin{tabular}{|c|c|c|c|c|}
\hline $\begin{array}{l}\text { Weighting } \\
\text { (\% of factor variance) }\end{array}$ & Question & $\begin{array}{l}\text { Grading scale } \\
\text { (outcomes in rank order) }\end{array}$ & Notes & Result and grade selected \\
\hline $42.42 \%$ & $\begin{array}{l}\text { Historic listing or } \\
\text { overlay? }\end{array}$ & $\begin{array}{l}\text { No. Very High } \\
\text { Yes. Very low. }\end{array}$ & $\begin{array}{l}\text { Buildings without historic listing or overlay } \\
(75.89 \%) \text {. } \\
\text { Buildings with heritage listing or overlay } \\
(24.11 \%) \text {. }\end{array}$ & \\
\hline $32.58 \%$ & The age of building? & $\begin{array}{l}19-41 \text { years. Very high. } \\
>42 \text { years. Low. } \\
\leq 18 \text { years. Very low. }\end{array}$ & $\begin{array}{l}19-42 \text { years }(72.89 \%) . \\
>42 \text { years }(21.47 \%) . \\
\leq 18 \text { years }(5.64 \%) .\end{array}$ & \\
\hline $25.00 \%$ & Aesthetic quality? & $\begin{array}{l}\text { Quite attractive. Very high. } \\
\text { Very attractive. Very high. } \\
\text { Neither attractive nor ugly. Medium. } \\
\text { Not very attractive. Low. } \\
\text { Very unattractive. Very low. }\end{array}$ & $\begin{array}{l}\text { Quite attractive (35.78\%). } \\
\text { Very attractive buildings (29.47\%). } \\
\text { Neither attractive nor ugly (19.85\%). } \\
\text { Not very attractive (12.71\%). } \\
\text { Very unattractive (2.20\%). }\end{array}$ & \\
\hline Total 100 & & & & \\
\hline
\end{tabular}

Fig. 6. 'Alterations and extensions' adaptations predictive model - factor three (social)

The first attribute, heritage listing is weighted at $42.42 \%$ and is very important within this factor. The second attribute building age is weighted at $32.58 \%$. Buildings less than 18 years of age are very unlikely to undergo work, whereas property aged between 19 and 41 years is very likely to have good potential for 'alterations and extensions' adaptations.

The final attribute, aesthetics is weighted at $25.00 \%$ of the factor with more attractive stock having a greater likelihood of adaptation. In summary for factor three, a listed building, over 42 years of age and very unattractive scores very low, whereas an unlisted building aged 25 years which is quite attractive scores very high.

\subsection{The PAAM tested - illustrative case study}

This section discusses and demonstrates the application of the PAAM to a real building as an illustrative case study.

\subsubsection{Building description}

447 Collins Street is a 27 storey purpose built office tower constructed between 1960 and 1965 (Land Victoria 2010a). The building occupies a low prime location on the Melbourne CBD's best street. It is a very good site because of the large area of open space, the plaza, directly in front of the building which offers great infill development potential (Land Victoria 2010a, 2010b). The building is located upon a $6,394 \mathrm{~m}^{2}$ site, with frontages of 70.9 metres to the north and south, and 90.2 metres on both east and west sides. The building is 93 metres high and is constructed using a concrete frame with wrap around marble clad balconies to all el- evations (see Fig. 7 and Fig. 8). The architectural style is the International style which was popular however the building is not listed. A three level podium faces onto Flinders Lane with an entrance to one of Melbourne's earliest underground car parks. Five additional storeys were added in 1982-1983. The building has approximately $30,737 \mathrm{~m}^{2}$ of Net Lettable Area and 300 car parks (City Scope Online 2010).

The building has some minor defects; however most are internal and superficial. A series of within use 'alterations' adaptations have taken place during the building's lifecycle; the most recent was completed on the upper levels during 1999-2001 (City Scope Online 2010). The building is now perceived to be suffering some physical obsolescence, and may require updating to attract long-term tenancies. Additionally, due to the property's age, it is unlikely that it can fully support a modern office environment, thus the building suffers some technological obsolescence. The internal condition of the property is considered average to above average upon the basis of age. Minor wear and tear is visible throughout the inspected areas, with particular weathering evident on the exterior of the property.

The structural elements of the property are sound, with only minor chips evident on the columns found in the loading dock area. As with many CBD office buildings of the era, the greatest risk faced by 447 Collins Street is its ability to attract and retain quality long-term tenants. Significant works would be required to bring the building back towards an 'A' Grade standard. However, the site is in a low prime location and if economically viable, it provides a significant opportunity for redevelopment or extension of the existing building. 


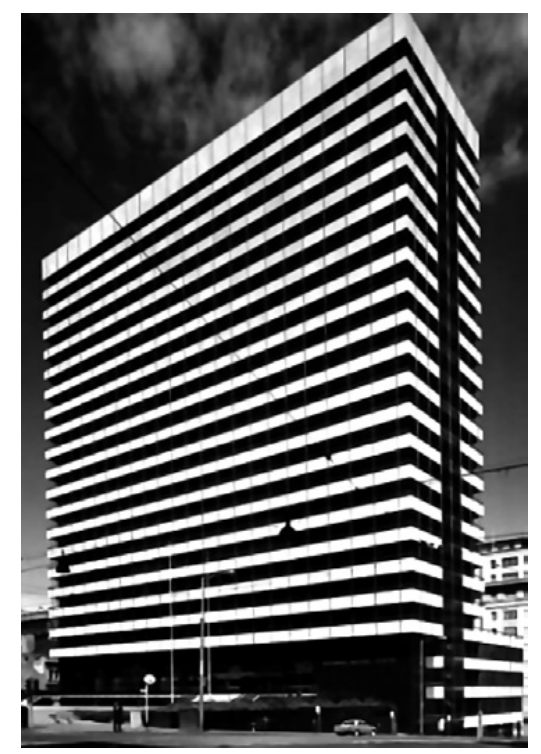

Fig. 7. 447 Collins street Melbourne circa 1965

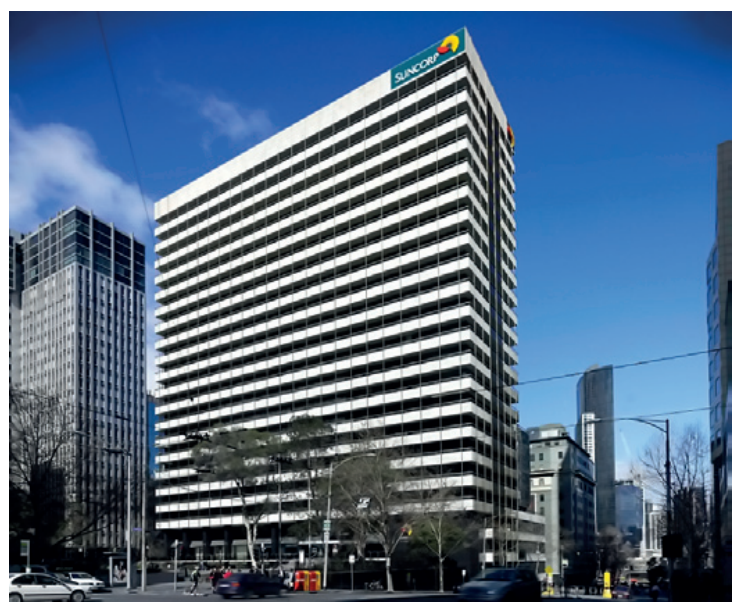

Fig. 8. 447 Collins street Melbourne circa 2011

\subsubsection{Building assessment for 'alterations and extensions' adaptation}

A PAAM checklist was used to assess the potential of the building for alterations adaptations and the summarised results are presented in Table 3.

The results show that overall 447 Collins Street has a consistently 'very high' potential across all three factors for 'alterations and extensions' adaptation. Within factor one physical and size, there is little variation within the six attributes with four scoring 'very high'. Overall physical and size potential is ranked as 'very high/high'. Factor two land potential shows the building has 'very high' potential for adaptation, with two of three attributes scoring very highly. Factor three covers the social potential for adaptation and an overall result of 'very high' is recorded. Finally assessment of the three factors together derives the overall potential of the building for 'alterations and extensions' adaptations which is 'very high'.

\section{DISCUSSION}

During the initial investigation of adaptation options stakeholders, including non-experts, will be able to use the model to determine overall potential, focussing at the outset on the property attributes which account for most variance in adaptation. With this approach property attributes which do not account for variance in adaptation are not taken into account because the PCA retains only the important attributes. The consideration of unimportant attributes is an issue with existing decision making tools which either considered all attributes equally or ascribed weightings based on

Table 3. Case Study - 447 Collins Street

\begin{tabular}{|c|c|c|c|}
\hline Factor & Attribute & Data & Results \\
\hline \multirow{7}{*}{$\begin{array}{l}\text { Physical and size } \\
\text { potential }\end{array}$} & Number of storeys? & 27 & High \\
\hline & Gross Floor Area? & $26241 \mathrm{~m}^{2}$ & Very high \\
\hline & Existing Property Council of Australia building quality grade? & $\mathrm{B}$ & Very high \\
\hline & The degree of attachment to other buildings? & Detached & Very high \\
\hline & Typical floor area? & $1689 \mathrm{~m}^{2}$ & Very low \\
\hline & Site access? & All sides & Very low \\
\hline & Physical and size result overall Very high/high & & \\
\hline \multirow[t]{4}{*}{ Land potential } & The street frontage of the building? & $40.00 \mathrm{~m}$ & Very high \\
\hline & The vertical services location? & Elsewhere & Very low \\
\hline & Location of the building? & Low Prime & Very high \\
\hline & Land result overall Very high & & \\
\hline \multirow[t]{5}{*}{ Social potential } & Historic listing or overlay relating to the building? & No & Very high \\
\hline & Age of building? & 35 years & Very high \\
\hline & The buildings aesthetics? & Not very attractive & Low \\
\hline & Social result overall & & Very high \\
\hline & Overall result & & Very high \\
\hline
\end{tabular}


expert opinion and or a limited number of cases (Bullen, Love 2011; Remøy, van der Voordt 2007; Arge 2005; Chudley 1981; Langston, Shen 2007; Kincaid 2002; Arup 2008). In this respect the model represents an original approach and contribution to knowledge and an important step forward in the decision-making process where adaptation is being considered as an option. A limitation of this approach is that the model looks at adaptation based on what has happened in this market in the period 1998 to 2008 and it does not look at prevailing market conditions at this level of preliminary decision-making.

The predictive model presented here evaluates the potential of commercial office buildings for 'alterations and extension' adaptation based on a decision model derived from an extensive literature review (Wilkinson et al. 2009; Wilkinson, Reed 2011). A simple weighted model based on extensive and intensive analysis of 5290 building adaptation events in the Melbourne CBD between 1998 and 2008 is a means of assessing initial adaptation potential. The PAAM model facilitates a relatively fast and deeper understanding of the adaptation potential of a building and highlights the important property attributes which are likely to present issues for stakeholders.

It has been shown via the illustrative case study how the PAAM operates in practice and the considerations undertaken at each stage. For each factor in the predictive model, possible answers are proposed based on the attributes to illustrate how the model determines very high to very low adaptation potential in a building. The model requires an assessment of each attribute within each factor as shown in the case study. The degree of importance of each factor and each attribute within each factor is known. The PAAM is based on the analysis of 5290 adaptation events and the results are based on a detailed study of building adaptation of a magnitude not previously undertaken. Finally the model explains $73 \%$ of variance in alterations and extension adaptations.

The PAAM takes the assessor through a series of stages and significantly does not require them to possess high levels of professional knowledge or technical competence. The assessor is able to use the case study checklist and PAAM model to determine the suitability of a building for adaptation based on the empirical analysis of thousands of adaptation events. At each stage the assessor deliberates only the most important property attributes. For each factor in the model, building profiles are suggested based on the attributes to illustrate how the model can determine high to low adaptation potential. Furthermore the exploratory case study illustrates how the model and checklist works in practice. Following extensive modelling with a number of different quantitative weighting approaches in the predictive models it was decided that a purely quantitative assessment was not sufficiently robust and reliable.

\section{CONCLUSIONS}

There were attributes which previous studies had identified as being important to building adaptation but which were found to be unimportant in explaining variance in adaptation in Melbourne in the PCAs or were not possible to test in this study (Wilkinson, Reed 2011). The first group, unimportant attributes, can be explained partly because of high levels of homogeneity in the stock, for example the attribute 'proximity to public transport' revealed that because the CBD is so well serviced by public transport all buildings were located within more or less equal distances to transport services. Homogeneity explains attributes such as parking provision, building classification, planning zones and environmental rating.

A further limitation of the approach is that the model is derived from an analysis of past practices. In undertaking an assessment the assessor does not consider current property market and general economic conditions within the PAAM, these factors are outside of the scope of the model.

It is noted that the importance of environmental attributes in the model is likely to change going forward as more buildings become rated for their environmental features. The emergence of the rating tools from 2006 onwards meant that only two years of adaptations would cover any environmental rating assessment in the database. It was not possible to collect some of the data to test some attributes such as 'water use pre and post adaptation' because of the retrospective nature of the study. Furthermore some data would not be stored by all owners such as the presence of toxins before and after adaptation. Such data is detailed, rich in nature but requires extensive data collection and there was insufficient time to collect such data whilst analysing such high numbers of adaptations.

In closing this research shows which property attributes are most important in adaptation based on the analysis of all events during an extended time period, and as a result, a preliminary assessment of adaptation model is proposed (PAAM). The PAAM does provide a decision-making tool for non- 
experts to make an initial evaluation of potential based on empirical evidence. The PAAM has been discussed with an illustrative case study to demonstrate how the model might be applied in practice. This research highlights a method which might lead to more evidence based decision-making in respect of building adaptation as humankind seeks solutions to the challenges of reducing the environmental footprint of our urban settlements.

\section{REFERENCES}

Arge, K. 2005. Adaptable office buildings: theory and practice, Facilities 23(3-4): 119-127. http://dx.doi. org/10.1108/02632770510578494

Arup. 2008. Existing buildings. Survival strategies. Melbourne.

Ball, R. M. 2002. Re use potential and vacant industrial premises: revisiting the regeneration issue in Stokeon-Trent, Journal of Property Research 19(2): 93110. http://dx.doi.org/10.1080/09599910210125223

Blakstad, S. H. 2001. A strategic approach to adaptability in office buildings. Doktor Ingenior thesis. Faculty of Architecture, Planning and Fine Arts, Norwegian University of Science and Technology.

Bullen, P. A.; Love, P. E. 2011. A new future for the past: a model for adaptive reuse decision-making, Built Environment Project and Asset Management 1(1): 32-44. http://dx.doi.org/10.1108/20441241111143768

Chudley, R. 1981. The maintenance and adaptation of buildings. London: Longman Group Limited.

City of Melbourne. 2005. City plan 2010. Towards a thriving and sustainable city. Melbourne, City of Melbourne.

City Scope Online. 2010. 447 Collins Street. [Online] RP Data - CityScope. Available at: www.cityscopeonline. com.au/DataView.aspx [accessed 18 March 2010]

De Vaus, D. 2002. Surveys in social research. $5^{\text {th }}$ edition. London: Routledge.

Douglas, J. 2006. Building adaptation. $2^{\text {nd }}$ ed. London: Butterworth-Heinemann.

DSE (2008) PRISM, Department of Sustainability and Environment (DSE), State Government of Victoria.

Hair, J. F.; Anderson, R. E.; Tatham, R. L.; Black, W. C. 1995. Multivariate data analysis. $4^{\text {th }}$ ed. Englewood Cliff, NJ: Prentice Hill.

Heath, T. 2001. Adaptive re-use of offices for residential use: the experiences of London and Toronto, $\mathrm{Ci}$ ties 18(3): 173-184. http://dx.doi.org/10.1016/S02642751(01)00009-9

Heikkila, E. J. 1992. Describing urban structure: a factor analysis of Los Angeles, Review of Urban and Regional Development Studies 4(1): 84-101. http:// dx.doi.org/10.1111/j.1467-940X.1992.tb00035.x

Horvath, R. J. 1994. National development paths 19651987: measuring a metaphor, Environment and Planning A 26(2): 285-305. http://dx.doi.org/10.1068/ a260285

Jolliffe, I. T. 2002. Principal component analysis. Springer Series in Statistics. Springer.
Kincaid, D. 2002. Adapting buildings for changing uses. Guidelines for change of use refurbishment. London: Spon Press.

Kucik, L. M. 2004. Restoring life: the adaptive reuse of a sanatorium. Master of Architecture thesis. School of Architecture and Interior Design, Cincinnati, University of Cincinnati.

Land Victoria. 2010a. 447 Collins street basic property report. [Online] LandVic. Available at: http://services.land.vic.gov.au/landchannel/content/propertyRep ort?actionField=viewReportandreportType=11andpr opertyIdentifier $=213478088$ andreportSeed $=$ ADDRE SS [accessed 19 March 2010]

Land Victoria. 2010b. 447 Collins street planning property report. [Online] LandVic. Available at: http:// services.land.vic.gov.au/landchannel/content/propert yReport?actionField=viewReportandreportType $=12 \mathrm{a}$ ndpropertyIdentifier $=213478088$ andreportSeed $=\mathrm{AD}$ DRESS [accessed 19 March 2010]

Langston, C.; Shen, L. Y. 2007. Application of the adaptive reuse potential model in Hong Kong: a case study of Lui Seng Chun, International Journal of Strategic Property Management 11(4): 193-207. http://dx.doi.or g/10.1080/1648715X.2007.9637569

Lorenz, D.; Heard, B.; Hoekstra-Fokkink, L.; Orchard, J.; Valeri, S. 2008. Towards a city of Melbourne climate change adaptation strategy: a risk assessment and action plan. Melbourne, Vic: Maunsell Australia Pty Ltd.

Ohemeng, F. 1996. The application of multi-attirbute theory to building rehabilitation versus redevelopment options. COBRA, RICS.

Property Council of Australia. 2007. Benchmarks survey of operating costs. Melbourne office buildings. Property Council of Australia.

Property Council of Australia. 2008. Existing buidlings / survival strategies. A toolbox for re-energising tired assets. Property Council of Australia.

Remøy, H. T.; van der Voordt, T. J. M. 2007. A new life: conversion of vacant office buildings into housing, Facilities 25(3/4): 88-103. http://dx.doi. org/10.1108/02632770710729683

RPData. 2008. Melbourne Cityscope, Cityscope Publications Pty Ltd.

Smith, L. I. 2002. A tutorial on principal component analysis. [Online] Available at: http://www.sccg. sk/ haladova/principal_components.pdf [accessed 17 April 2012]

Wilkinson, S. J.; James, K.; Reed, R. 2009. Using building adaptation to deliver sustainability in Australia, Structural Survey 27(1): 46-61. http://dx.doi. org/10.1108/02630800910941683

Wilkinson, S. J. 2011. The relationship between building adaptation and property attributes. $\mathrm{PhD}$ thesis, Deakin University. Available at: http://dro.deakin. edu.au/view/DU:30036710 [accessed 24 September 2012]

Wilkinson, S. J.; Reed, R. 2011. Examining and quantifying the drivers behind alterations and extensions to commercial buildings in a central business district, Construction Management and Economics 29(7): 725-735. http://dx.doi.org/10.1080/01446193. 2011.588954 